\title{
Novel high resolution method for visualization of regional ventricular wall motion and blood flow by 3 T MRI Stig F Samnøy*1, Aasmund Kvamme ${ }^{2}$, Gottfried Greve ${ }^{1,3}$ and Terje H Larsen ${ }^{1,3}$
}

\begin{abstract}
Address: ${ }^{1}$ Haukeland University Hospital, Bergen, Norway, ${ }^{2}$ Bergen University College, Bergen, Norway and ${ }^{3}$ University of Bergen, Bergen, Norway
\end{abstract} * Corresponding author

from 13th Annual SCMR Scientific Sessions

Phoenix, AZ, USA. 21-24 January 2010

Published: 21 January 2010

Journal of Cardiovascular Magnetic Resonance 20 I0, I2(Suppl I):P234 doi:I0.I I86/I532-429X-I2-SI-P234

This abstract is available from: http://jcmr-online.com/content/I2/SI/P234

(C) 2010 Samnøy et al; licensee BioMed Central Ltd.

\section{Introduction}

Alteration in myocardial wall motion may be related to e.g. coronary artery disease. Dysfunctional wall motion may also influence on the blood flow pattern throughout the cardiac cycle. Assessing the wall motion and blood flow is therefore important for detecting regional left ventricular dysfunction and abnormal flow patterns.

\section{Purpose}

Using a time-resolved 3D MRI velocity mapping technique, the aim of this study was to develop an improved tool for quantification and visualization of both regional ventricular wall motion and the corresponding intracavity blood flow pattern.

\section{Methods}

Three dimensional phase shift velocity mapping were utilized to obtain velocity measurements from the left ventricular wall and the intracavity blood. The scanner used for the acquisitions was a 3.0 T GE Signa Excite, and sequence parameters were $\mathrm{TR}=11 \mathrm{~ms}$, TE $=4 \mathrm{~ms}$, Flip Angle $=20$, Slice Thickness $=8 \mathrm{~mm}$, Matrix $=128 \times 256$. Data from a full $3 \mathrm{D}$ volume were acquired to carry out the velocity mapping technique on successive slices covering the entire left ventricle throughout the cardiac cycle.

By adding three separate velocity components in every pixel the resultant vector was constructed to get the true 3D direction and velocity throughout the cardiac cycle. Software based on Java has been developed for the quan- tification and visualization of the $3 \mathrm{D}$ velocity vectors. The velocity pattern for both the ventricular wall and blood flow were superimposed on transparent images and visualized in a fully rotatable and scalable 3D frame. The length and color of the 3D vectors visualize the strength and direction of the movement at every voxel.

\section{Results}

By applying 3D phase shift velocity mapping on a full 3D volume of the left ventricle the software was able to simultaneously calculate and present time-dependent velocity vectors in the same visual model for both the ventricular wall and blood flow. This was performed using data from

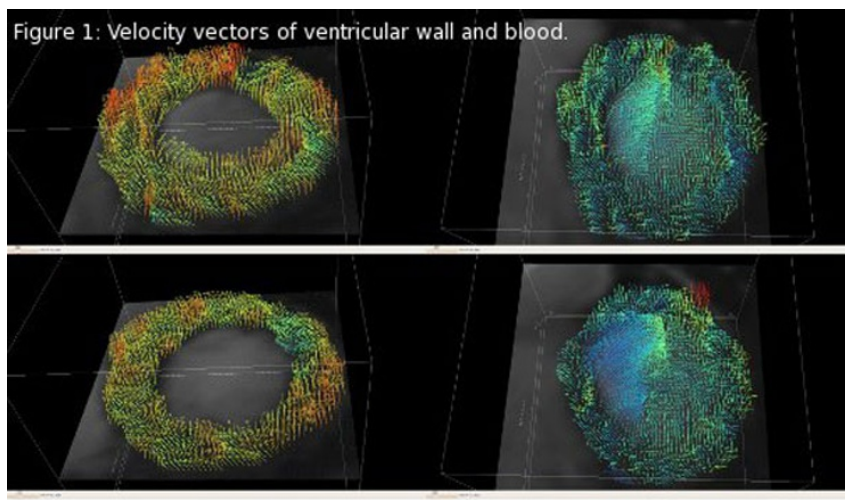

Figure I

Velocity vectors of ventricular wall and blood. 
controls and patients with myocardial infarction. Figure 1 shows samples of wall and blood velocity vectors at different time intervals at a patient with myocardial infarction.

\section{Conclusion}

This software utilizes 3D MRI velocity mapping and improves the ability to study simultaneously regional velocity patterns of the left ventricle and the corresponding intracavity blood velocity pattern. The visualization technique reflects time-dependent velocities and reveal regional difference in tissue blood reserve and function, and also in the blood velocity pattern. Moreover, the technique may reveal hypokinetic and akinetic contractions, as well as asyncronous and dyskinetic wall movements.

Publish with Bio Med Central and every scientist can read your work free of charge

"BioMed Central will be the most significant development for disseminating the results of biomedical research in our lifetime. "

Sir Paul Nurse, Cancer Research UK

Your research papers will be:

- available free of charge to the entire biomedical community

- peer reviewed and published immediately upon acceptance

- cited in PubMed and archived on PubMed Central

- yours - you keep the copyright 